Original article

\title{
Study on Lipid Profile in Offspring of Dyslipidemic Parents
}

\author{
MKH Azad ${ }^{1}$, SS Hussain ${ }^{1}$, MBK Choudhury ${ }^{2}$, FR Mowsumi ${ }^{3}$ \\ ${ }^{1}$ Department of Biochemistry, North East Medical College, Sylhet, ${ }^{2}$ OSD, DG-Health, Mohakhali, Dhaka, ${ }^{3}$ National \\ Mushroom Development and Extension Center, Savar, Dhaka
}

\begin{abstract}
As dyslipidemia is responsible for remarkable cause of cardiovascular disease which is considered as the number one cause of death globally, this study was undertaken to evaluate the lipid profile status of offspring of dyslipidemic parents in comparison with the offspring of normolipidemic parents. In this study, carried out on 89 subjects, the mean total cholesterol (TC), triglyceride (TG), high density lipoprotein (HDL-c) and low density lipoprotein (LDL-c) were 162.18 \pm 20.97, $168.98 \pm 33.51,39.09 \pm 3.62$ and 90.41 \pm 18.64 $\mathrm{mg} / \mathrm{dl}$ respectively in adolescents with parental dyslipidemia and 158.38 \pm 12.67, 157.22 \pm 15.06, 40.51 \pm 2.90 and $86.42 \pm 12.39 \mathrm{mg} / \mathrm{dl}$ respectively in control adolescents. There were significant differences ( $p<0.05$ ) of TG and HDL-c between cases and controls where HDLc choesterol was significantly lower in offspring of dyslipidemic parents then the offspring of normolipidemic parents. The findings of this study reflect the association of offspring dyslipidemia with parental dyslipidemia, probably due to some genetic predisposition. Offspring of dyslipidemic parents have higher levels of TC, TG, LDL-c and lower level of HDL-c compared to age and sex matched control subjects.

Key words: Offspring, Dyslipidemia, TC, TG, HDL-c, LDL-c. Here dyslipidaemia is considered as hyperlipidaemia
\end{abstract}

\section{Introduction}

Cardiovascular disease (CVD) is the number one cause of death globally and is projected to remain the leading cause of death. An estimated 17.5 millions people of died from CVD in 2005, representing $30 \%$ of all global deaths ${ }^{1}$. Dyslipidemias are disorders of lipoprotein metabolism which may result in hyperlipidaemia or hypolipidaemia. Among the dyslipidaemias hyperlipidaemia is the most common and world wide problem. Epidemiologic studies in children establish a strong statistical association between childhood overweight and hyperlipidaemia. Other risk factors of dyslipidaemias includes familial hypercholesterolemia, familial hypercholesterolemia, familial defective apoprotein-B, and familial hypertriglyceridemia. There may be dyslipidaemia of some secondary causes which includes nephritic syndrome, diabetes mellitus, and hypothyroidism ${ }^{3}$.

Many studies have demonstrated that atherosclerosis has its silent beginning during childhood. Genetic component is believed to be the more predominant factor for coronary atherosclerosis early in life ${ }^{4}$. Patients with familial hyperlipidemia have a high incidence of premature coronary disease and many epidemiological studies have demonstrated a positive correlation between mean population plasma cholesterol concentration and morbidity and death from coronary disease ${ }^{5}$. More than half of patients with angiographically confirmed coronary artery disease (CAD) before age 60 years have a familial lipoprotein disorder ${ }^{6}$.
Dyslipidemia were defined $\mathrm{TC} \geq 240 \mathrm{mg} / \mathrm{dl}$, HDL-c $<40 \mathrm{mg} / \mathrm{dl}$, LDL-c $\geq 160 \mathrm{mg} / \mathrm{dl}$ and $\mathrm{TG} \geq 200 \mathrm{mg} / \mathrm{dl}$ in adults, according to National Cholesterol Education Program

Adult Treatment Panel-III (NCEP ATP-III) $2002^{7}$. Adolescent is defined by WHO as a person between 10-19 years of age ${ }^{8}$. In children and adolescents, dyslipidemia were defined as TC $\geq 200 \mathrm{mg} / \mathrm{dl}$, LDL-c $\geq 130$ $\mathrm{mg} / \mathrm{dl}$ according to National Cholesterol Education Program (NCEP) Expert Panel on Blood Cholesterol Levels in Children and Adolescents ${ }^{9}$, TG levels > $150 \mathrm{mg} / \mathrm{dl}$ and HDL-c levels $<40 \mathrm{mg} / \mathrm{dl}^{10}$. For children in general, borderline levels of TC and LDL-c are defined as 170-199 and 110-129 mg/dl, respectively ${ }^{11}$.

Dyslipidemia rarely leads to adverse health outcome in childhood, but its long term effects may be considerable. Large epidemiologic studies indicate that children's lipid levels correlate with those of adult family members. Children of parents with CHD have a higher prevalence of dyslipidemia in childhood, and identification of dyslipidemia in children can identify families at increased risk for CHD. Identifying children with dyslipidemia could lead to interventions or treatments that could prevent or delay adult dyslipidemia and $\mathrm{CHD}^{2}$.

\section{Subjects and Methods}

The study was carried out in the the Department of Biochemistry and Department of Cardiology of Sylhet MAG Osmani Medical College, during the period of January 2007 to December 2007. 89 
adolescents aged 10-19 years of selected hyperlipidaemic parents were taken as samples. 44 offspring of parents with known and biochemically proven dyslipidemia were considered as case (group-I) and 45 offspring of parents (both) without history and biochemically proven dyslipidemia were taken as control (group-II). Patients attending the out patients setup of cardiology department and admitted in the coronary care unit were considered as parents of cases and controls were taken from general population. Dyslipidemia of parents were defined as NCEP ATP-III Guidelines $2002^{7}$.

Estimation of serum TC, TG, HDL-c, LDL$c$, glucose and creatinine were done. The results were expressed as mean $\pm \mathrm{SD}$. All statistical analyses were done by SPSS software program, using Student's unpaired ' $\mathrm{t}$ ' test. A level of $\mathrm{p}<0.05$ was accepted as statistically significant.

\section{Results}

In group-I, the mean of TC, TG, HDL-c and LDL-c were $162.18 \pm 20.97,168.98 \pm 33.51$, $39.09 \pm 3.62$ and $90.41 \pm 18.64 \mathrm{mg} / \mathrm{dl}$ respectively. In group-II, the mean of TC, TG, HDL-c, and LDL-c levels were 158.38 $\pm 12.67,157.22 \pm 15.06,40.51 \pm 2.90$ and $86.42 \pm 12.39 \mathrm{mg} / \mathrm{dl}$ respectively. There was significant difference of HDL-c and TG between cases and controls $(\mathrm{p}<0.05)$ (Table-I).

Table-I: Comparison of lipid profile between .group-I and group-II.

\begin{tabular}{llll}
\hline Parameter $(\mathrm{mg} / \mathrm{dl})$ & Group-I $(\mathrm{n}=44)$ & Group-II $(\mathrm{n}=45)$ & $\mathrm{p}$ \\
& Mean $\pm \mathrm{SD}$ & Mean \pm SD & \\
\hline TC & $162.18 \pm 20.97$ & $158.38 \pm 12.67$ & $>0.05$ \\
TG & $168.98 \pm 35.51$ & $157.22 \pm 15.06$ & $<0.05$ \\
HDL-c & $39.09 \pm 3.62$ & $40.51 \pm 2.90$ & $<0.05$ \\
LDL-c & $90.41 \pm 18.64$ & $86.42 \pm 12.39$ & $>0.05$
\end{tabular}

Means compared using Student's unpaired ' $t$ ' test.

Table-II shows the lipid profile status in dyslipidemic parents and normolipidemic parents. In normolipidemic parents, TC, TG, HDL-c and LDL-c levels are $177.42 \pm$ $18.25,178.06 \pm 13.48,41.94 \pm 2.28$ and $98.89 \pm 18.43 \mathrm{mg} / \mathrm{dl}$ respectively. In dyslipidemic parents, TC, TG, HDL-c and LDL-c were $216.76 \pm 31.63,274.04 \pm 65.37$, $37.28 \pm 8.78$ and $126.16 \pm 26.82 \mathrm{mg} / \mathrm{dl}$ respectively. There was a highly significant mean difference $(\mathrm{p}<0.001)$ of TC, TG, LDL-c and significant mean difference $(\mathrm{p}<$ 0.05) of HDL-c between dyslipidemic parents and normolipidemic parents.
Table-II: Comparison of lipid profile between dyslipidemic parents and normolipidemic parents.

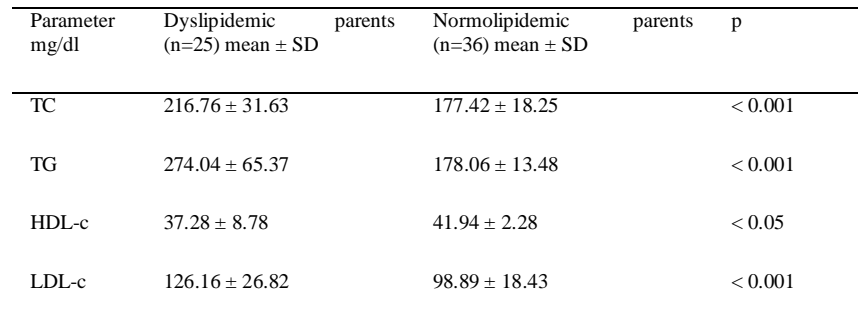

Means compared using Student's unpaired ' $t$ ' test.

\section{Discussion}

Dyslipidemia is a conventional risk factor for CVD and also for cerebrovascular diseases in most cases ${ }^{12}$. Family history of parental dyslipidemia is one of the major factors to be considered in the decision of assessing the lipid profile in children and adolescents ${ }^{7}$. The aim of this study was to test the hypothesis that dyslipidemia in offspring is associated with dyslipidemia in parents in our population. Fasting serum lipid profile status were estimated in adolescents with documented parental dyslipidemia and compared these values with lipid profile of adolescents with no history and biochemically proven parental dyslipidemia to assess whether there is any association between lipid levels of parents with their offspring.

Analyzed data showed that there were significant differences $(p<0.05)$ of TG and HDL-c between cases and controls in this study. The mean of TG in cases and controls were 168.98 and 157.22 $\mathrm{mg} / \mathrm{dl}$ respectively which were much higher than the study done by Rahman $(2000)^{13}(105.81 \mathrm{mg} / \mathrm{dl})$ and considerably very much higher than the United States data $(72 \mathrm{mg} / \mathrm{dl})$ and the study was done by Mendes et al. (2006) ${ }^{14}$ (86.2 and 76.0 $\mathrm{mg} / \mathrm{dl}$ in cases and control respectively). The mean levels of HDL-c in cases and controls were 39.09 and $40.51 \mathrm{mg} / \mathrm{dl}$ respectively in present study which is consistent with the study done by Gulati and Suxena $(2003)^{4}$ (mean 38.8 and by Rahman (2000) ${ }^{13}$ in Bangladeshi children $(36.12 \mathrm{mg} / \mathrm{dl}$ ) and lower than the data from similar study by Mendes et al. $(2006)^{14}(44.5$ and $51.2 \mathrm{mg} / \mathrm{dl}$ in cases and control respectively) and much lower than the United States data (52.6 $\mathrm{mg} / \mathrm{dl})$ and Schulpis and Karikas $(1998)^{13}$ (59-64 mg/dl). Recent studies showed that high TG and low HDL-c 
may be an atherosclerotic determinant ${ }^{15}$. The mean plasma TC levels were similar to study done by Schulpis and Karikas $(1998)^{16}(157 \mathrm{mg} / \mathrm{dl}$ in boys and $172 \mathrm{mg}$ / dl in girls) and slightly lower than United States data $(170 \mathrm{mg} / \mathrm{dl})^{17}$. No significant difference was observed in TC level between cases and control in this study.

In present study, the mean levels of LDL-c in cases and controls were 90.41 and $86.42 \mathrm{mg} / \mathrm{dl}$ respectively which were somewhat similar to the study done by Gulati and Saxena $(2003)^{4}$ and was considerably low than the similar study done by Mendes et al. (2006) ${ }^{14}(144.2$ and $100.4 \mathrm{mg} / \mathrm{dl}$ in cases and control respectively). There was no significant difference in LDL-c levels in this study between the cases and controls.

Dyslipidemia is a well established risk factor for cardiovascular disease. Mendes et al. (2006) ${ }^{14}$ found significantly higher levels of TC, LDL-c and lower level of HDL-c in a study, but no significant difference was found in level of TG between cases and controls. In this study we found significantly higher levels of TG and lower levels of HDL-c in cases compared to controls but no significant difference were observed in TC and LDL-c. The comparatively lower levels of TC, HDL-c and higher levels of TG in the current study are consistent with the observations of generally lower values in less developed countries ${ }^{15}$.

\section{Conclusion}

The findings of this study reflect the association of offspring dyslipidemia with parental dyslipidemia, probably due to some genetic predisposition. Offspring of dyslipidemic parents have higher levels of lipid profile status compared to age and sex matched controls. If parents with dyslipidemia become more conscious about their status and lead life more carefully, the rate of dislipidemic offspring will be lower.

\section{References}

1. WHO Global InfoBase: Bangladesh: All Data. 2007, Cholesterol, Raised. http://www.who.int/infobase.

2. Haney EM, Huffman LH, Bougatsos C, Freeman M, Steiner RD, Nelson HD. Screening and Treatment for Lipid Disorders in Children and Adolescents: Systematic Evidence Review for the US Preventive Services Task Force. Pediatrics 2007; 120(1): 89-214.

3. US Preventive Services Task Force. Screening for Lipid Disorders in Children: US Preventive Services Task Force Recommendation Statement. Pediatrics 2007; 120(1): 215-219.

4. Gulati S, Saxena A. Study of Lipid Profile in Children of Patients with Premature Coronary Artery Disease. Indian Pediatrics 2003; 40: 556-560.

5. Boon NA, Fox KAA. Diseases of the cardiovascular system. In CRW Edwards , IAD Bouchier, C Haslett, ER Chilvers ( eds ), Davidson's principle and practice of medicine, 17 th edn, Churchill Livingstone, New York 1999: pp. 191-312.

6. Dammerman M, Breslow JL. Genetic Basis of Lipoprotein Disorders. Circulation 1995; 91: 505-512.

7. National Cholesterol Education Program. Detection, Evaluation and Treatment of High Blood Cholesterol in Adults (Adult Treatment Panel III), 2002. National Heart, Lung and Blood Institute, National Institutes of Health.

8. World Health Organization. The Adolescent Health \& Development (AHD) unit - Investigating in a health sector responseto Adolescents \& Young people 2008.

http//www.searo.who.int/en/Section13/Secti on1245.htm.

9. Lauer RM, Barness LA, Clark R, Deckelbaum RJ, Finberg L, Kwiterovich PO. Highlights of the Report of the Expert Panel on Blood Cholesterol Levels in Children and Adolescents 1991.US Department of Health and Human Services.

10. Painter PC, Cope JY, Smith JL. 2001Refference Information for the Clinical Laboratory. In : Tietz Fundamentals of Clinical Chemistry, CA Burtis, ER Ashwood (eds), 5th edn, Saunders, Pennsylvania, 2001 : pp.9551028.

11. American Diabetes Association .2003Management of Dyslipidemia in Children and Adolescents with Diabetes. Diabetes Care 2003; 26: 2194-2197.

12. Begum RA. Study of Serum Homocysteine Concentration in Patients with Stroke 2007. M. Phil Thesis (Biochemistry), SOMC. 
13. Rahman T. A study on the lipid profile of Bangladeshi children 2000. MD Thesis (Paediatrics), BSMMU, Dhaka.

14. Mendes GA, Martinez TL, Izar MC, Amancio OM, Novo NF, Matheus SC, et al. Lipid Profile and Nutrition Counceling Effects in Adolescents With Family History of Premature Coronary Artery Disease. Arquivos Brasileiros de Cardiologia 2006; 86: 5 .

15. Chakraborty B, Ali ML, Perveen S, Khan MK. Relation of High TG (Triglyceride) and Low HDL (High Density Lipoprotein) with Coronary Artery Disease - An Analysis. Journal of Bangladesh College of Physicians and Surgeons 2003; 21(1):1419.
16. Schulpis K, Karikas GA. Serum cholestero and triglyceride distribution in 7767 School aged Greek children. Pediatrics 1998; 101:861-864.

17. American Heart Association. Heart Disease and Stroke Statistics-2008 Updates 2008. American Heart Association. 